\title{
Glucose and insulin exert additive ocular and renal vasodilator effects on healthy humans
}

\author{
A. Luksch ${ }^{1}$, K. Polak ${ }^{1}$, B.Matulla ${ }^{1}$, S. Dallinger ${ }^{1}$, S. Kapiotis ${ }^{2}$, G. Rainer ${ }^{3}$ M. Wolzt ${ }^{1}$, L. Schmetterer ${ }^{4}$, \\ ${ }^{1}$ Department of Clinical Pharmacology, University of Vienna, Austria \\ ${ }^{2}$ Department of Laboratory Medicine, University of Vienna, Austria \\ ${ }^{3}$ Department of Ophthalmology, University of Vienna, Austria \\ ${ }^{4}$ Institute of Medical Physics, University of Vienna, Austria
}

\section{Abstract}

Aims/hypothesis. There is evidence that insulin and glucose cause renal and ocular vasodilation. There is, however, currently no data on the effect of combined hyperglycaemia and hyperinsulinaemia on the renal and ocular blood flow seen in diabetic patients on insulin therapy.

Methods. We carried out two different 3-way crossover studies in healthy subjects (each, $n=9$ ). In study one, hyperglycaemic clamps $(5.6 \mathrm{mmol} / 1,11.1 \mathrm{mmol} /$ $1,16.7 \mathrm{mmol} / \mathrm{l})$ were carried out during placebo or insulin (dose 1: $1 \mathrm{mU} / \mathrm{kg} / \mathrm{min}$; dose $2: 2 \mathrm{mU} / \mathrm{kg} / \mathrm{min}$ ) infusion. The second study was identical but endogenous insulin secretion was blocked with somatostatin. The renal plasma flow, glomerular filtration rate and pulsatile choroidal blood flow were measured using the paraaminohippurate method, the inulin method and a laser interferometric measurement of fundus pulsation amplitude, respectively.
Results. Insulin increased renal plasma flow and fundus pulsation amplitude but not the glomerular filtration rate. Hyperglycaemia increased all the renal and ocular parameters studied. Haemodynamic effects of glucose and insulin were additive when somatostatin was co-administered but not under basal conditions. Conclusions/interpretation. Glucose and insulin can exert additive vasodilator properties on renal and ocular circulation. To find out whether this observation is related to the increased regional perfusion in diabetes longitudinal studies on patients with Type I (insulin-dependent) diabetes mellitus are needed. [Diabetologia (2001) 44: 95-103]

Keywords Insulin, glucose, ocular blood flow, renal blood flow, human, clinical trial, healthy subjects, choroidal blood flow, glomerular filtration rate.
The pathogenesis of diabetic vascular complications in the eye and kidney of humans is still not clear. There is evidence that glomerular filtration rate and renal plasma flow increase during poor metabolic control in patients with Type I (insulin-dependent) diabetes mellitus [1-3]. Several authors have also ob-

Received: 1 August and in revised form: 22 September 2000

Corresponding author: L. Schmetterer, MD, Department of Clinical Pharmacology, Währinger Gürtel 18-20, A-1090 Vienna, Austria

Abbreviations: RPF, Renal plasma flow; GFR, glomerular filtration rate; $\mathrm{PAH}$, paraaminohippurate; FPA, fundus pulsation amplitude; MAP, mean arterial pressure. served increased retinal and choroidal blood flow in patients with early diabetes [4-8], although there is some evidence of decreased ocular perfusion [9-10]. It has been suggested that this hyperperfusion in the kidney and the eye could predispose patients to develop vascular complications in these organs [11-14].

Insulin treatment in patients with Type I diabetes induces peripheral blood hyperinsulinaemia in order to suppress interprandial hepatic glucose release. $\mathrm{Pa}$ tients treated for Type I diabetes are therefore exposed to high plasma concentrations of glucose and insulin. It has been known for a long time that a rapid increase in glucose plasma concentrations could cause vasodilation in the renal and ocular vasculature [15-16]. More recently it has been reported that insu- 


\begin{tabular}{|c|c|c|c|c|c|c|c|c|c|c|}
\hline Scheduled time & $\begin{array}{l}-75 \\
\min \end{array}$ & $\begin{array}{l}-55 \\
\min \end{array}$ & $\begin{array}{l}-10 \\
\min \end{array}$ & $\begin{array}{c}0 \\
\min \end{array}$ & $\begin{array}{c}45 \\
\min \end{array}$ & $\begin{array}{c}60 \\
\min \end{array}$ & $\begin{array}{l}105 \\
\min \end{array}$ & $\begin{array}{l}120 \\
\min \end{array}$ & $\begin{array}{l}165 \\
\min \end{array}$ & $\begin{array}{l}180 \\
\min \end{array}$ \\
\hline Resting time & $\mathrm{X}$ & & & & & & & & & \\
\hline \multicolumn{11}{|l|}{ PAH infusion for $235 \mathrm{~min}$} \\
\hline \multicolumn{11}{|l|}{ Insulin infusion for $235 \mathrm{~min}$} \\
\hline \multicolumn{3}{|l|}{ Insulin or placebo infusion for $190 \mathrm{~min}$} & \\
\hline \multicolumn{11}{|l|}{$\begin{array}{l}\text { Somatostatin infusion for } 190 \mathrm{~min} \text { (protocol B } \\
\text { only) }\end{array}$} \\
\hline \multicolumn{11}{|l|}{$\begin{array}{l}\text { Glucose infusion for } 60 \text { minutes to maintain } \\
\text { plasma concentrations at } 100 \mathrm{mg} / \mathrm{dl}\end{array}$} \\
\hline \multicolumn{11}{|l|}{$\begin{array}{l}\text { Glucose infusion for } 60 \text { minutes to maintain } \\
\text { plasma concentrations at } 200 \mathrm{mg} / \mathrm{dl}\end{array}$} \\
\hline \multicolumn{11}{|l|}{$\begin{array}{l}\text { Glucose infusion for } 60 \text { minutes to maintain } \\
\text { plasma concentrations at } 300 \mathrm{mg} / \mathrm{dl}\end{array}$} \\
\hline Blood sampling for $\mathrm{PAH}$, inulin & & $\bar{X}$ & $\bar{X}$ & & $\bar{X}$ & & $\bar{X}$ & & $\mathrm{X}$ & \\
\hline Fundus pulsation measurement & & $\mathrm{X}$ & $\mathrm{X}$ & & $\mathrm{X}$ & & $\mathrm{X}$ & & $\mathrm{X}$ & \\
\hline Blood pressure and pulse rate & & $\mathrm{X}$ & $\mathrm{X}$ & & $\mathrm{X}$ & & $\mathrm{X}$ & & $\mathrm{X}$ & \\
\hline Blood sampling for insulin, glucose, and C peptide & & & $\mathrm{X}$ & & $\mathrm{X}$ & & $\mathrm{X}$ & & $\mathrm{X}$ & \\
\hline
\end{tabular}

Fig. 1. Study schedule. Three study days were scheduled for each subject. Day A: Placebo + glucose; day B: Insulin (1 mU/ $\mathrm{kg} / \mathrm{min})+$ glucose; day C: Insulin $(2 \mathrm{mU} / \mathrm{kg} / \mathrm{min})+$ glucose. In protocol $\mathrm{B}$ endogenous insulin secretion was blocked by somatostatin

lin could also cause vasodilation [17]. The combined effects of insulin and glucose have been studied locally in the human forearm $[18,19]$ but no data are available for the eye and kidney of humans.

We investigated renal and ocular haemodynamic responses to hyperglycaemia at different plasma insulin concentrations. Renal plasma flow (RPF), glomerular filtration rate (GFR) and pulsatile choroidal blood flow were measured using the paraaminohippurate $(\mathrm{PAH})$ method, the inulin method and laser interferometric measurement of fundus pulsation, respectively.

\section{Subjects and methods}

The studies were done according to the GCP guidelines and were approved by the ethics committee of the Vienna University School of Medicine. In the pilot study 8 healthy men volunteers were studied (age range 19-28 years). The main studies were carried out in 18 healthy men volunteers (age range: $21-35$, means \pm SD: $24.2 \pm 4.2$ ). The study was explained to all volunteers who gave their written consent before participating. Each subject underwent screening that included medical history and a physical examination, a 12-lead electrocardiogram, a complete blood count, activated partial thromboplastin time, thrombin time, fibrinogen, clinical chemistry (sodium, potassium, creatinine, uric acid, glucose, cholesterol, triglycerides, alanine aminotransferase, aspartate transcarbamylase, $\gamma$-glutamyltransferase, alkaline phosphatase, total bilirubin, total protein), hepatitis A, B, C and HIV-serology, urine analysis, urine drug-screening, and an oral glucose tolerance test (OGTT). Subjects were excluded if any abnormality was found except when the investigators considered the abnormality to be clinically irrelevant. Furthermore an ophthalmic examination, including slit lamp biomicroscopy and indirect fundusco- py, was carried out. Inclusion criteria were normal ophthalmic findings and ametropia of 3 diopters or less.

Pilot study. To investigate potential haemodynamic effects of intravenous low dose somatostatin on renal and ocular blood flow a pilot study was carried out. Eight healthy subjects were included in this study and received an infusion of $0.1 \mu \mathrm{g} / \mathrm{kg} / \mathrm{min}$ somatostatin (UCB Pharma, Vienna, Austria) over $180 \mathrm{~min}$ in an open design. RPF, GFR and ocular fundus pulsation amplitude (FPA) were measured every 60 min during the study.

Study design. Two different studies were carried out. In protocol A, the haemodynamic effects of hyperglycaemic insulin clamps were investigated $(n=9)$. In protocol $\mathrm{B}$, the haemodynamic effect of hyperglycaemic insulin clamps were studied during simultaneous inhibition of endogenous insulin secretion by somatostatin $(n=9)$. Both studies followed a randomised balanced 3-way cross-over design with washout periods of at least 4 days between trial days. The study schedule is given in Fig. 1. Subjects received the following treatment on separate study days:

Treatment A: Placebo, glucose (at a rate to maintain glucose plasma levels at $5.6 \mathrm{mmol} / 1,11.1 \mathrm{mmol} / 1,16.7 \mathrm{mmol} / \mathrm{l}$, respectively)

Treatment B: $1 \mathrm{mU} / \mathrm{kg} / \mathrm{min}$ Insulin, glucose (glucose plasma levels at $5.6 \mathrm{mmol} / 1,11.1 \mathrm{mmol} / \mathrm{l}, 16.7 \mathrm{mmol} / \mathrm{l}$, respectively)

Treatment C: $2 \mathrm{mU} / \mathrm{kg} / \mathrm{min}$ Insulin, glucose (glucose plasma levels at $5.6 \mathrm{mmol} / 1,11.1 \mathrm{mmol} / 1,16.7 \mathrm{mmol} / 1$, respectively)

Drugs. The following drugs were given intravenously:

Insulin (Huminsulin, Lilly; Fegersheim, France) 1 or $2 \mathrm{mU} /$ $\mathrm{kg} / \mathrm{min}$, infused over $180 \mathrm{~min}$.

Glucose (glucose $20 \%$, Leopold Infusionsflaschen, Leopold Pharma, Linz, Austria) at a rate appropriate to maintain plasma glucose concentrations at $5.6 \mathrm{mmol} / 1,11.1 \mathrm{mmol} / \mathrm{l}$, $16.7 \mathrm{mmol} / \mathrm{l}$, respectively. A maximum deviation of approximately $20 \%$ was allowed for plasma glucose during the euglycaemic and hyperglycaemic insulin clamps.

Somatostatin (UCB Pharma, Vienna, Austria) $0.1 \mu \mathrm{g} / \mathrm{kg} /$ min, infused over $180 \mathrm{~min}$.

$\mathrm{KCl}$ (Kaliumchlorid Leopold $20 \%$ Infusionszusatz, Leopold Pharma, Linz, Austria) at a rate of $10 \mathrm{mmol} / \mathrm{h}$ (if indicated).

Paraaminohippurate (PAH, Aminohippurate Sodium, MSD, West Point, Penn., USA) $8 \mathrm{mg} / \mathrm{kg}$ bolus, continuous infusion to attain $0.02 \mathrm{mg} / \mathrm{ml} \mathrm{PAH}$ plasma concentration over $225 \mathrm{~min}$ at an estimated clearance of $750 \mathrm{ml} / \mathrm{min}$. 
Table 1. Effects of somatostatin in the pilot study

\begin{tabular}{|c|c|c|c|c|}
\hline & Baseline & $60 \mathrm{~min}$ & $120 \mathrm{~min}$ & $180 \mathrm{~min}$ \\
\hline Mean blood pressure $(\mathrm{mm} \mathrm{Hg})$ & $83 \pm 4$ & $83 \pm 3$ & $84 \pm 3$ & $83 \pm 3$ \\
\hline Pulse rate (beats/min) & $59 \pm 7$ & $59 \pm 7$ & $60 \pm 6$ & $59 \pm 7$ \\
\hline Renal plasma flow (ml/min) & $860 \pm 71$ & $785 \pm 50 *$ & $769 \pm 47 *$ & $759 \pm 56^{*}$ \\
\hline Fundus pulsation amplitude $(\mu \mathrm{m})$ & $4.0 \pm 1.1$ & $3.9 \pm 1.2$ & $4.0 \pm 1.2$ & $4.0 \pm 1.3$ \\
\hline
\end{tabular}

* Asterisks indicate significant differences from baseline $(p<0.05)$. Data are presented as means $\pm \operatorname{SD}(n=8)$

Inulin (Laevosan, Linz, Austria) $37.5 \mathrm{mg} / \mathrm{kg}$ bolus, continuous infusion to attain $0.25 \mathrm{mg} / \mathrm{ml}$ plasma concentration over $225 \mathrm{~min}$ at an estimated clearance of $140 \mathrm{ml} / \mathrm{min}$.

Physiologic saline solution as placebo, infused over $180 \mathrm{~min}$

Study protocol. Before trial days subjects fasted overnight. When steady state conditions were reached - verified by repeated blood pressure measurements during the resting period - PAH and inulin infusions were started. After 45 min baseline measurements were done. These were carried out in a predetermined order (blood sampling, fundus pulsation measurement, blood pressure and pulse rate). The time schedule of measurements is shown in Fig. 1. All haemodynamic measurements were carried out in the last $10 \mathrm{~min}$ of each plasma glucose concentration. Heart rate and real time ECG were measured continuously during drug treatment.

Study methods. Insulin clamps: Euglycaemic and hyperglycaemic insulin clamps were done as described previously [20]. Each clamp was started with a primed infusion of insulin for $8 \mathrm{~min}$ followed by a constant infusion rate of either $1 \mathrm{mU} / \mathrm{kg} /$ $\mathrm{min}$ or $2 \mathrm{mU} / \mathrm{kg} / \mathrm{min}$. Somatostatin was only infused in the second study (protocol B). If necessary, potassium was infused to prevent hypokalemia. Glucose was infused at the rate needed to maintain the blood glucose at the required concentrations. For this purpose glucose concentration was measured using arterialized venous blood samples, which were drawn every 5 min from the contralateral arm placed in a heating box. Glucose plasma concentrations were measured using a glucose analyzer (Beckman Glucose Analyzer 2, Beckman Instruments Inc, Fullerton, Calif., USA). Insulin and C-peptide plasma concentrations were measured by routine laboratory procedures at scheduled time points.

We measured blood pressure, pulse rate, ECG and Mean arterial blood pressure (MAP) on the upper arm using an automated oscillometric device. The pulse rate was automatically recorded using a finger pulse-oxymetric device. The ECG and heart rate were monitored using a standard 4 lead device (HP-CMS patient monitor, Hewlett Packard, Palo Alto, Calif., USA).

PAH technique: RPF was assessed using the PAH plasma clearance method [21]. We measured PAH-plasma concentrations at baseline and during drug administration at scheduled time points by photometric analysis.

Inulin technique: GFR was assessed using the inulin plasma clearance method [21]. We measured inulin-plasma concentrations at baseline and during drug administration at scheduled time points using a commercially available kit (Laevosan, Linz, Austria).

Fundus pulsations: We assessed pulse synchronous pulsations of the ocular fundus by means of laser interferometry on the subject's right eye according to the method described previously [22]. The eye is illuminated by a beam from a single mode laser diode with a wavelength $(\lambda)$ of $783 \mathrm{~nm}$. The light is reflected at the front side of both the cornea and the retina. The beam focus at the fundus has a diameter of $20-50 \mu \mathrm{m}$.
The reflection from the posterior segment probably occurs because of the retinal pigment epithelium or Bruch's membrane. The two re-emitted waves produce interference fringes which can be used to calculate the distance changes between the cornea and retina during a cardiac cycle. Distance changes between the cornea and retina are reflected in variations in the interference order $(\Delta \mathrm{N}(\mathrm{t}))$. Changes in the interference order can be assessed by counting the fringes moving inwards and outwards during the cardiac cycle. Changes in optical distance $(\Delta \mathrm{L}(\mathrm{t}))$, corresponding to the cornea-retina distance changes, can then be calculated using $\Delta \mathrm{L}(\mathrm{t})=\Delta \mathrm{N}(\mathrm{t}) \cdot \lambda / 2$. The maximum distance change is called FPA and measures the local pulsatile blood flow [23]. The short-term and day-to-day variability of the method is small, allowing even small changes in local pulsatile blood flow to be detected [22]. The macula, where the retina lacks vasculature, was chosen to be measured to obtain information on the choroidal blood flow.

Data analysis. For data description haemodynamic parameters were expressed as per cent change from baseline $(\Delta \%)$. Statistical analysis was done using absolute values. The effect of somatostatin in the pilot experiment was assessed by Friedman ANOVA. Effects of insulin and glucose on haemodynamic parameters were analysed by repeated measure ANOVA. A $p$ value of less than 0.05 was considered significant. For data description, values are given as means \pm SD.

\section{Results}

Pilot study. The results of the pilot study are presented in Table 1. Somatostatin did not influence blood pressure or pulse rate and had no effect on FPA. Somatostatin infusion, however, caused a decrease in RPF $(-12 \pm 5 \% ; p<0.001$ vs baseline) and a less pronounced decrease in GFR $(-6 \pm 3 \%, p<0.001$ vs baseline).

Protocol $A$. The baseline levels of all outcome variables for the three study days are shown in Table 2 . Insulin on its own did not affect the blood pressure or pulse rate (Table 3 ). The effects of insulin and glucose on renal and ocular haemodynamic variables are presented in Fig. 2. Hyperinsulinaemia at normal plasma glucose concentrations increased RPF $(1 \mathrm{mU} / \mathrm{kg} / \mathrm{min}: \quad 4 \pm 7 \%, \quad 2 \mathrm{mU} / \mathrm{kg} / \mathrm{min}: \quad 8 \pm 5 \%$; $p=0.04$ versus placebo) but did not influence GFR. The effect of insulin during normoglycaemia on FPA was also significant $(1 \mathrm{mU} / \mathrm{kg} / \mathrm{min}: 9 \pm 4 \%, 2 \mathrm{mU} / \mathrm{kg} /$ $\min : 10 \pm 7 \% ; p=0.02$ versus placebo).

Hyperglycaemia did not affect the blood pressure or the pulse rate on the placebo day (Table 3). RPF 
Table 2. Baseline haemodynamic variables (protocols A and B)

\begin{tabular}{|c|c|c|c|}
\hline & Day 1 & Day 2 & Day 3 \\
\hline $\begin{array}{l}\text { Protocol A } \\
\text { Mean blood pressure }(\mathrm{mm} \mathrm{Hg}) \\
\text { Pulse rate (beats/min) } \\
\text { Renal plasma flow }(\mathrm{ml} / \mathrm{min}) \\
\text { Glomerular filtration rate }(\mathrm{ml} / \mathrm{min}) \\
\text { Fundus pulsation amplitude }(\mu \mathrm{m})\end{array}$ & $\begin{aligned} 81 & \pm 14 \\
71 & \pm 11 \\
775 & \pm 74 \\
127 & \pm 16 \\
4.0 & \pm 1.4\end{aligned}$ & $\begin{aligned} 83 & \pm 14 \\
64 & \pm 9 \\
750 & \pm 86 \\
134 & \pm 13 \\
4.0 & \pm 1.4\end{aligned}$ & $\begin{aligned} 82 & \pm 9 \\
68 & \pm 11 \\
759 & \pm 65 \\
135 & \pm 14 \\
3.9 & \pm 1.3\end{aligned}$ \\
\hline $\begin{array}{l}\text { Protocol B } \\
\text { Mean blood pressure }(\mathrm{mm} \mathrm{Hg}) \\
\text { Pulse rate }(\text { beats/min }) \\
\text { Renal plasma flow }(\mathrm{ml} / \mathrm{min}) \\
\text { Glomerular filtration rate }(\mathrm{ml} / \mathrm{min}) \\
\text { Fundus pulsation amplitude }(\mu \mathrm{m})\end{array}$ & $\begin{aligned} 81 & \pm 8 \\
53 & \pm 7 \\
832 & \pm 86 \\
126 & \pm 13 \\
3.8 & \pm 1.5\end{aligned}$ & $\begin{aligned} 83 & \pm 5 \\
60 & \pm 12 \\
807 & \pm 82 \\
129 & \pm 7 \\
4.0 & \pm 1.7\end{aligned}$ & $\begin{aligned} 81 & \pm 7 \\
61 & \pm 9 \\
803 & \pm 100 \\
128 & \pm 12 \\
3.8 & \pm 1.6\end{aligned}$ \\
\hline
\end{tabular}

Data are presented as means \pm SD (each $n=9)$.

Table 3. Blood pressure and pulse rate during the 3 study days (protocols A and B)

\begin{tabular}{|c|c|c|c|c|}
\hline & Baseline & $60 \mathrm{~min}$ & $120 \mathrm{~min}$ & $180 \mathrm{~min}$ \\
\hline $\begin{array}{l}\text { Protocol A } \\
\text { Placebo } \\
\text { Mean blood pressure }(\mathrm{mm} \mathrm{Hg}) \\
\text { Pulse rate (beats/min) }\end{array}$ & $\begin{array}{l}84 \pm 15 \\
71 \pm 11\end{array}$ & $\begin{array}{l}86 \pm 18 \\
62 \pm 9\end{array}$ & $\begin{array}{l}80 \pm 16 \\
71 \pm 13\end{array}$ & $\begin{array}{l}81 \pm 16 \\
71 \pm 13\end{array}$ \\
\hline $\begin{array}{l}\text { Insulin }(1 \mathrm{mU} / \mathrm{kg} / \mathrm{min}) \\
\text { Mean blood pressure }(\mathrm{mm} \mathrm{Hg}) \\
\text { Pulse rate (beats/min) }\end{array}$ & $\begin{array}{l}83 \pm 13 \\
65 \pm 10\end{array}$ & $\begin{array}{l}81 \pm 11 \\
69 \pm 10\end{array}$ & $\begin{array}{l}79 \pm 15 \\
70 \pm 12\end{array}$ & $\begin{array}{l}79 \pm 12 \\
71 \pm 9\end{array}$ \\
\hline $\begin{array}{l}\text { Protocol B } \\
\text { Placebo } \\
\text { Mean blood pressure }(\mathrm{mm} \mathrm{Hg}) \\
\text { Pulse rate (beats/min) }\end{array}$ & $\begin{array}{l}82 \pm 5 \\
61 \pm 11\end{array}$ & $\begin{array}{l}79 \pm 5 \\
56 \pm 7 *\end{array}$ & $\begin{array}{l}80 \pm 7 \\
51 \pm 7 *\end{array}$ & $\begin{array}{l}79 \pm 9 \\
54 \pm 9^{*}\end{array}$ \\
\hline
\end{tabular}

All haemodynamic measurements were carried out in the last 10 minutes of each plasma glucose concentration. Data are presented as means $\pm \mathrm{SD}$ (each $n=9$ ).

* Asterisks indicate significant differences from baseline $(p<0.05)$.

$(11.1 \mathrm{mmol} / \mathrm{l}: \quad 9 \pm 4 \%, \quad 16.7 \mathrm{mmol} / \mathrm{l}: \quad 20 \pm 9 \%$; $p<0.001$ vs baseline) and GFR (11.1 mmol/l: $7 \pm 5 \%, 16.7 \mathrm{mmol} / \mathrm{l}: 9 \pm 8 \% ; p<0.010$ vs baseline) increased significantly when glucose plasma concentrations were in the hyperglycaemic range (Fig.2). Fundus pulsation amplitude (FPA) also increased during hyperglycaemia $(11.1 \mathrm{mmol} / \mathrm{l}: \quad 17 \pm 9 \%$, $16.7 \mathrm{mmol} / \mathrm{l}: 24 \pm 8 \% ; p<0.001$ vs baseline) and this effect was even more pronounced than in the kidney.

Systemic, renal or ocular haemodynamic variables were not different between placebo and glucose infusion and co-infusion of insulin and glucose infusion (repeated measure ANOVA). At a glucose plasma concentration of $11.1 \mathrm{mmol} / \mathrm{l} \mathrm{RPF}$ increased by $9 \pm 4 \%$ during placebo, by $11 \pm 6 \%$ during $1 \mathrm{mU} / \mathrm{kg} /$ min insulin and by $11 \pm 10 \%$ during $2 \mathrm{mU} / \mathrm{kg} / \mathrm{min}$ insulin). The effects of $16.7 \mathrm{mmol} / \mathrm{l}$ glucose on RPF were similar during placebo and insulin infusion (Fig. 2). The effects of hyperglycaemia on GFR and FPA were also similar during placebo and insulin. For example the effect of $16.7 \mathrm{mmol} / 1$ glucose on FPA was $24 \pm 8 \%$ during placebo infusion, $28 \pm 10 \%$ during $1 \mathrm{mU} / \mathrm{kg} / \mathrm{min}$ and $30 \pm 11 \%$ during $2 \mathrm{mU} / \mathrm{kg} /$ min.

The effects of insulin and glucose infusion on insulin, glucose and C-peptide plasma concentrations are shown in Table 4. Glucose plasma concentrations were in the range expected. In fact, mean glucose plasma concentrations were within $10 \%$ of the target value for all infusion periods. Insulin plasma concentrations increased during all the study days. This increase was less pronounced on the placebo day than on the insulin days. The increase in insulin plasma concentrations during hyperglycaemia without insu- 

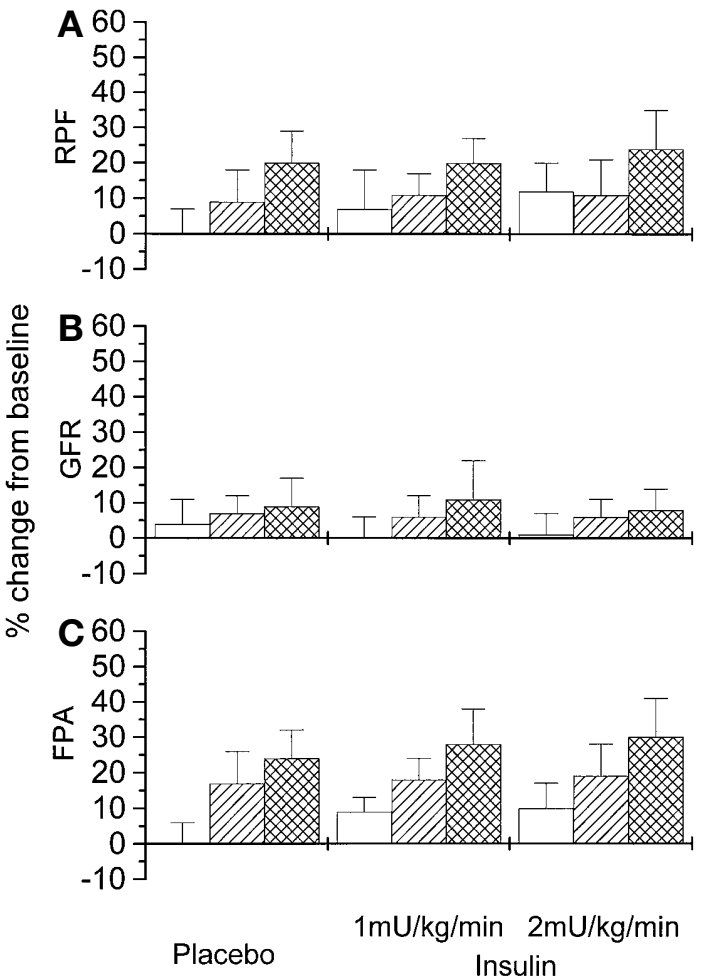

Fig. 2. The effect of insulin and glucose on renal plasma flow, glomerular filtration rate and fundus pulsation amplitude (protocol A). Open bars indicate plasma glucose of $5.6 \mathrm{mmol} / \mathrm{l}$, striped bars indicate $11.1 \mathrm{mmol} / \mathrm{l}$ plasma glucose and hatched bars indicate $16.7 \mathrm{mmol} / \mathrm{l}$ plasma glucose. All haemodynamic measurements were carried out in the last $10 \mathrm{~min}$ of each plasma glucose level. Data are presented as percent change from baseline (means $\pm \mathrm{SD}, n=9$ )

lin infusion was caused by an endogenous insulin release. The increase in C-peptide plasma concentrations provides further evidence for this.

Protocol $B$. The baseline levels of all outcome variables on the three study days are shown in Table 2. Infusion of insulin and somatostatin did not influence blood pressure or pulse rate (Table 3 ). The renal and ocular haemodynamic variables during hyperglycaemic insulin clamps with somatostatin infusion are presented in Fig.3. Hyperinsulinaemia reversed the somatostatin-induced decrease in RPF (somatostatin alone: $-6 \pm 4 \%$ somatostatin $+1 \mathrm{mU} / \mathrm{kg} / \mathrm{min}: 1 \pm 5 \%$, somatostatin $+2 \mathrm{mU} /$ $\mathrm{kg} / \mathrm{min}$ : $4 \pm 5 \% ; p=0.003$ vs somatostatin only). In contrast infusion of somatostatin + insulin had no effect on GFR. Insulin increased FPA significantly during somatostatin infusion $(1 \mathrm{mU} / \mathrm{kg} / \mathrm{min}$ : $10 \pm 5 \%, 2 \mathrm{mU} / \mathrm{kg} / \mathrm{min}: 13 \pm 7 \% ; p<0.001$ vs somatostatin only).

Hyperglycaemia did not affect blood pressure but decreased pulse rate $(p=0.003)$ on the placebo day where somatostatin only was given (Table 3 ). RPF (somatostatin alone: $-6 \pm 4 \%, 11.1 \mathrm{mmol} / \mathrm{l}:-1 \pm 5 \%$,
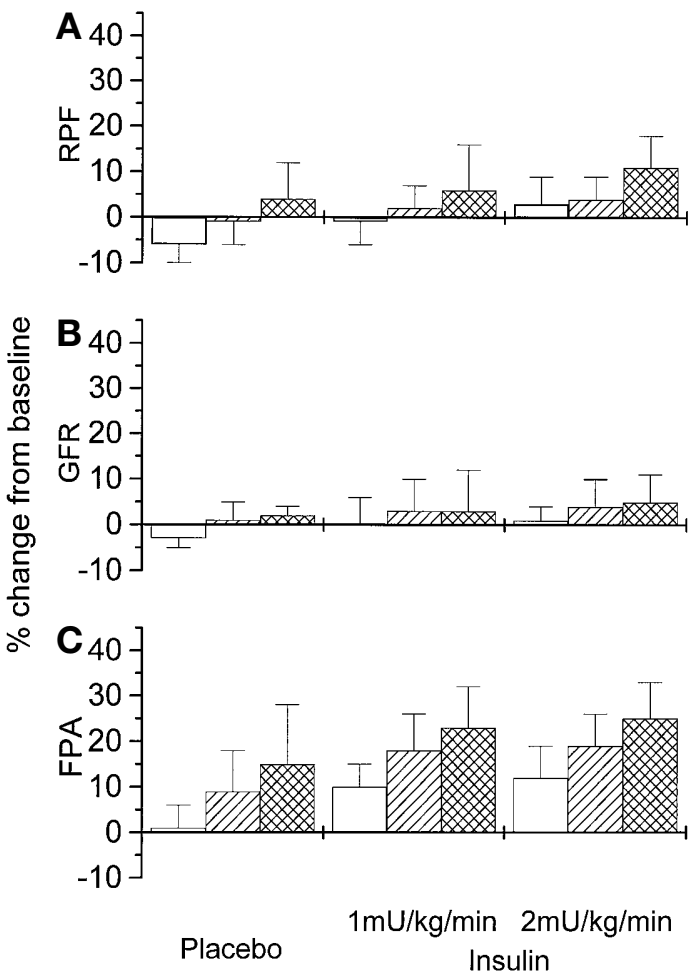

Fig. 3. The effect of insulin and glucose on renal plasma flow, glomerular filtration rate and fundus pulsation amplitude during somatostatin infusion (protocol B). Open bars indicate plasma glucose of $5.6 \mathrm{mmol} / \mathrm{l}$, striped bars indicate $11.1 \mathrm{mmol} /$ 1 plasma glucose and hatched bars indicate $16.7 \mathrm{mmol} / \mathrm{l}$ plasma glucose. All haemodynamic measurements were carried out in the last 10 minutes of each plasma glucose level. Data are presented as percent change from baseline (means $\pm \mathrm{SD}, n=9$ )

$16.7 \mathrm{mmol} / \mathrm{l}: 4 \pm 8 \% ; p=0.003$ vs baseline) and GFR (somatostatin alone: $-3 \pm 2 \%, 11.1 \mathrm{mmol} / 1: 1 \pm 4 \%$, $16.7 \mathrm{mmol} / \mathrm{l}: 2 \pm 2 \% ; p=0.002$ vs baseline) increased significantly when plasma glucose concentrations increased as shown in Fig. 3. FPA also increased during hyperglycaemia (FPA: $11.1 \mathrm{mmol} / \mathrm{l}: \quad 9 \pm 9 \%$, $16.7 \mathrm{mmol} / \mathrm{l}: 16 \pm 13 \% ; p<0.001$ vs baseline).

The blood pressure, pulse rate and GFR were not different between the placebo/somatostatin/glucose infusion and the insulin/somatostatin/glucose infusion (repeated measure ANOVA). By contrast, the effects of glucose on RPF were more pronounced during hyperinsulinaemia than during placebo $(p=0.047)$. At $16.7 \mathrm{mmol} / \mathrm{l}$ glucose plasma concentration RPF increased by $4 \pm 8 \%$ during placebo, by $6 \pm 10 \%$ during $1 \mathrm{mU} / \mathrm{kg} / \mathrm{min}$ insulin and by $11 \pm 7 \%$ during $2 \mathrm{mU} / \mathrm{kg} / \mathrm{min}$ insulin. The effects of glucose and insulin on RPF were additive during blockade of endogenous insulin release. The same phenomenon was observed for FPA $(p=0.020)$. A glucose plasma concentration of $300 \mathrm{mg} / \mathrm{dl}$ increased FPA by $16 \pm 13 \%$ during placebo, by $23 \pm 9 \%$ during $1 \mathrm{mU} / \mathrm{kg} / \mathrm{min}$ insulin and by $25 \pm 8 \%$ during $2 \mathrm{mU} /$ $\mathrm{kg} / \mathrm{min}$ insulin. 
Table 4. Insulin, glucose and C-peptide plasma concentrations during the 3 study days (protocols A and B)

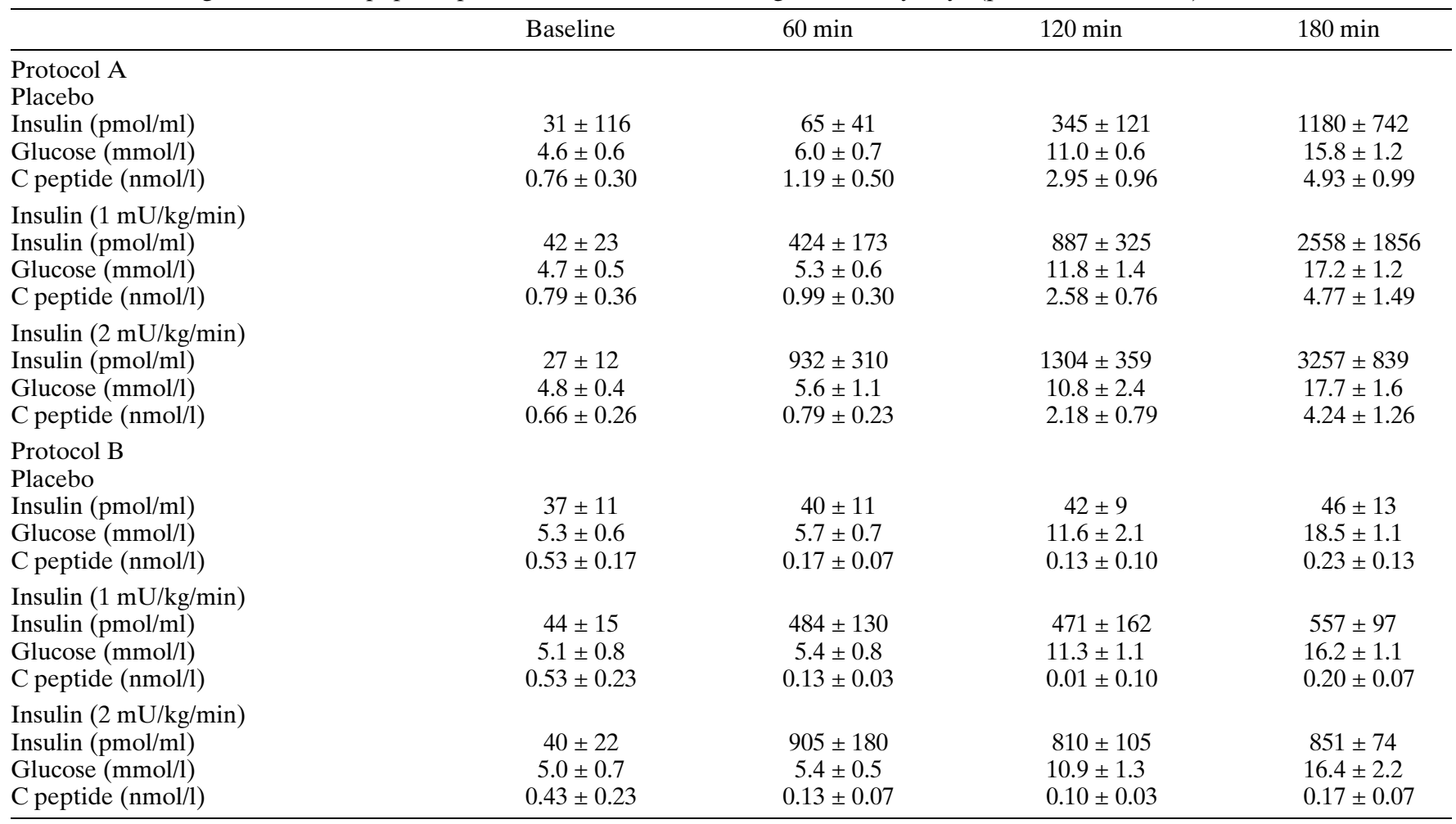

Data are presented as means $\pm \mathrm{SD}(n=9$, each $)$.

The effects of insulin and glucose infusion on insulin, glucose and C-peptide plasma concentrations are presented in Table 4. Again, glucose plasma concentrations were near the target values during all infusion periods. In contrast to protocol A, no increase in insulin plasma concentrations could be detected for hyperglycaemia and exogenous insulin increased insulin plasma concentration to a much smaller extent. The decrease in C-peptide plasma concentrations confirmed the efficacy of the blockade with somatostatin.

\section{Discussion}

In our study insulin increased in RPF and FPA, which is in accord with previous studies [24-26]. In addition, plasma glucose had a significant influence on regional perfusion in the eye and the kidney. This is in agreement with a number of other studies on humans which indicate that rapid increase in plasma glucose induces vasodilation in the kidney and increases GFR [15, 27-29]. Some reports, however, indicate decreased renal plasma flow after the fast administration of glucose [30]. Several animal and human studies have shown that retinal blood flow increases with increasing plasma glucose in the eye $[10,16,31]$, but this is the first study to show choroidal vasodilation during hyperglycaemia in humans.
The main finding of our study is, however, that insulin and glucose exert additive vasodilator effects at the level of the renal and ocular vasculature. In the kidney and the choroid, the effects of hyperglycaemia were more pronounced during hyperinsulinaemia than during placebo because of additional vasodilation caused by insulin. In protocol A, however, the effect of the co-infusion of placebo and glucose infusion was almost equal to the effect of the co-infusion of insulin and glucose infusion. The pronounced increase in insulin plasma concentrations during hyperglycaemia due to an endogenous insulin release was most likely responsible for the results in this part of our study. Our data therefore show that glucose administered to healthy subjects causes vasodilator effects which are attributable to increases in plasma glucose as well as to increases in plasma insulin concentrations. During hyperinsulinaemic, hyperglycaemia plasma insulin concentrations increased to values of more than $400 \mu \mathrm{U} / \mathrm{ml}$. This, however, did not increase renal or ocular blood flow, which indicates that the maximum vasodilatory on the concentration-response curve were reached. This agrees with a number of previous studies on different tissues $[17,26]$.

The vasodilator effects of glucose and insulin could interact in a complex way. There is evidence that the vasodilator effect of glucose is more pronounced for retinal vasculature than for insulin, be- 
cause an insulin bolus reduces retinal blood flow in patients with Type I diabetes by decreasing glucose plasma concentrations [32]. The increase in regional blood flow during hyperinsulinaemia appears to be primarily mediated by nitric oxide [25, 33-35]. The mechanism underlying the response of vasodilation to rapid glucose infusion is less clear. It has been suggested that a change in NADH: NAD + ratio could be responsible for the glucose-induced vasodilation but this hypothesis has yet to be confirmed in human beings [36]. Interestingly, rapid hyperglycaemia blunts endothelium-dependent vasodilation in the human forearm [37], which is most likely caused by the activation of protein kinase $\mathrm{C}$ [38]. Insulin and glucose could therefore exert complex interactions at the level of the vascular endothelium, but this needs to be investigated. In a previous study on rat skeletal muscle, hyperglycaemia modified the reaction of microvessels to insulin [39]. This effect was, however, not observed in the present in vivo study.

A comprehensive characterisation of insulin and glucose on kidney functions was beyond the scope of our study. Interestingly, insulin increased RPF but had no effect on GFR. There is still no detailed characterisation of insulin's effects on the human kidney although increased renal plasma flow during hyperinsulinaemia could contribute to the decrease in proximal tubular sodium reabsorption, which could be a compensatory mechanism for insulin-induced sodium retention $[24,40]$.

Our results could also be of relevance for understanding renal and ocular vascular disease in diabetes. In animal models, early structural and functional changes associated with diabetes include basement membrane thickening and increased local blood flow [41-43]. As mentioned, this is in accord with a variety of cross-sectional studies in human beings. Several hypothesis have tried to explain the association between increased perfusion and diabetic microvascular complications. Experimental evidence indicating that the onset and progression of diabetic nephropathy is linked to an increased intraglomerular capillary pressure [11] is compatible with a vasodilator effect of glucose on renal vessels. For ocular vasculature, it has been suggested that hyperperfusion could lead to endothelial damage and an altered autoregulation because of increased vessel wall shear stress [13, 14]. A major problem with extrapolating the present data to the pathologies observed in patients with diabetes is, however, that our data were obtained from short-term experiments. Whereas this study as well as reports from other groups clearly indicate vasodilator properties of insulin and glucose after fast exogenous administration no information on the long term haemodynamic effects is available. Further longitudinal studies, which focus on patients at the onset and on the very early stages of diabetes, are required to clarify this issue. Another important limitation of our study is that the experiments were not carried out in patients with Type I diabetes. The effects of hyperinsulinaemia on the absence and presence of high glucose need to be investigated for this group of patients. There is, however, some evidence that renal haemodynamic effects of hyperglycaemia are dependent on the stage of renal nephropathy [28].

Our study also shows that low dose somatostatin reduces renal but not ocular blood flow. This is compatible with previous studies $[44,45]$ in healthy subjects. The mechanism underlying this renal vasoconstrictor action is, however, not known. It could well be, however, that the ability to inhibit insulin secretion contributes to reduced RPF during somatostatin administration. In addition, it has been suggested that somatostatin could have a direct effect on vascular smooth muscle through a calcium-dependent mechanism [46].

The limitations of ocular fundus pulsation measurements have to be considered when discussing the results obtained in our study for the human choroid. There is evidence that FPA is an adequate measure of pulsatile choroidal blood flow [23, 47-49] but the steady component of choroidal blood flow cannot be assessed using this method. We cannot exclude entirely changes in flow pulsatility in the choroid during insulin and glucose infusion or both. These changes are assumed to be, however, small if systemic blood pressure and heart rate do not change [47]. In addition, care must be taken when extrapolating the present results to the microvasculature. In our study indices of organ blood flow were measured for the eye and kidney and no direct information on the microvasculature in the vascular beds was obtained. There is, however, evidence that the insulin induced increase in perfusion is accompanied by capillary recruitment in the leg muscle [50]. Our study does not indicate if this is also the case in the ocular and renal circulation.

To conclude, our data show that glucose and insulin have additive vasodilator effects on the eye and kidney. Whether this observation is related to increased regional perfusion in patients with diabetes requires longitudinal studies in patients with Type I diabetes.

Acknowledgements. We would like to thank the Österreichischer Hochschuljubiläumsfonds (University Jubilee Foundation; project number: 164/98) for their financial support.

\section{References}

1. Ditzel J, Junker K (1972) Abnormal glomerular filtration rate, renal plasma flow, and renal protein excretion in recent and short-term diabetes. BMJ 2: 13-19

2. Christiansen JS, Gammelgaard J, Frandsen M, Parving HH (1981) Increased kidney size, glomerular filtration rate and renal plasma flow in short-term insulin-dependent diabetics. Diabetologia 20: 451-456 
3. Winetz JA, Golbetz HV, Spencer RJ, Lee JA, Meyers BD (1982) Glomerular function in advanced human diabetic nephropathy. Kidney Int 21: 750-756

4. Grunwald JE, Riva CE, Sinclair SH, Brucker AJ, Petrig BL (1986) Laser Doppler velocimetry study of retinal circulation in diabetes mellitus. Arch Ophthalmol 104: 991-996

5. Patel V, Rassam S, Newsom R, Wiek J, Kohner E (1992) Retinal blood flow in diabetic retinopathy. BMJ 305: 678-683

6. Grunwald JE, DuPont J, Riva CE (1996) Retinal hemodynamics in patients with early diabetes mellitus. Br J Ophthalmol 80: 327-331

7. MacKinnon JR, O $\times$ Brien C, Swa K, Aspinall P, Butt Z, Cameron D (1997) Pulsatile ocular blood flow in untreated diabetic retinopathy. Acta Ophthalmol Scand 75: 661-664

8. Findl O, Dallinger S, Rami B et al. (2000) Ocular haemodynamics and color contrast sensitivity in patients with Type I diabetes. Br J Ophthalmol 43: 493-498

9. Langham ME, Grebe R, Hopkins S, Marcus S, Sebag M (1991) Choroidal blood flow in diabetic retinopathy. Exp Eye Res 52: 167-173

10. Bursell SE, Clermont AC, Kinsley BT, Simonson DC, Aiello LM, Wolpert HA (1996) Retinal blood flow changes in patients with insulin-dependent diabetes mellitus and no diabetic retinopathy. Invest Ophthalmol Vis Sci 37: 886-897

11. Hostetter TH, Rennke HG, Brenner BM (1982) The case for intraretinal hypertension in the initiation and progression of diabetic and other glomerulopathies. Am J Med 72: 375-380

12. Mogensen (1986) Early glomerular hyperfiltration in insulin-dependent diabetes and late nephropathy. Scand J Clin Lab Invest 46: 201-206

13. Kohner EM, Patel V, Rassam SM (1995) Role of blood flow and impaired autoregulation in the pathogenesis of diabetic retinopathy. Diabetes 44: 603-607

14. Schmetterer L, Wolzt M (1999) Ocular blood flow and associated functional deviations in diabetic retinopathy. Diabetologia 42: 387-405

15. Christiansen JS, Frandsen M, Parving HH (1981) Effect of intravenous glucose infusion on renal function in normal man and in insulin-dependent diabetics. Diabetologia 21: 368-373

16. Sullivan PM, Davies GE, Caldwell G, Morris AC, Kohner EM (1990) Retinal blood flow during hyperglycemia. A laser Doppler velocimetry study. Invest Ophthalmol Vis Sci 31: 2041-2045

17. Baron AD (1994) Hemodynamic actions of insulin. Am J Physiol 267: E187-E202

18. Ueda S, Petrie JR, Cleland SJ, Elliott HL, Connell JM (1998) The vasodilating effect of insulin is dependent on local glucose uptake: a double blind, placebo controlled study. J Clin Endocrinol Metab 83: 2126-2131

19. Cleland SJ, Petrie JR, Ueda S, Elliott HL, Connell JM (1999) Insulin-mediated vasodilation and glucose uptake are functionally linked in humans. Hypertension 33: 554-558

20. De Fronzo RA, Tobin JD, Andress R (1979) Glucose clamp technique: a method for quantifying insulin secretion and resistance. Am J Physiol 237: E214-E223

21. Schnurr E, Lahme W, Küppers H (1980) Measurement of renal clearance of insulin and $\mathrm{PAH}$ in the steady state without urine collection. Clin Nephrol 13: 26-29

22. Schmetterer L, Lexer F, Unfried C, Sattmann H, Fercher AF (1995) Topical measurement of fundus pulsations. Opt Eng 34: 711-716
23. Schmetterer L, Dallinger S, Findl O et al.(1998) Noninvasive investigations of the normal ocular circulation. Invest Ophthalmol Vis Sci 39: 1210-1220

24. Stenvinkel P, Bolinder J, Alvestrand A (1992) Effects of insulin on renal haemodynamics and the proximal and distal tubular sodium handling in healthy subjects. Diabetologia 35: 1042-1048

25. Schmetterer L, Müller M, Fasching P et al. (1997) Renal and ocular hemodynamic effects of insulin. Diabetes 46: 1868-1874

26. Polak K, Dallinger S, Polska E et al. (2000) Effects of insulin on retinal and pulsatile choroidal blood flow in humans. Arch Ophthalmol 118: 55-59

27. Greene SA, Dalton RN, Turner C, Haycock GB, Chantler C (1987) Hyperglycemia with and without glycosuria: effect on inulin and para-amino hippurate clearance. Kidney Int 32: 896-899

28. Remuzzi A, Viberti G, Ruggenenti P, Battaglia C, Pagni R, Remuzzi G (1990) Glomerular response to hyperglycemia in human diabetic nephropathy. Am J Physiol 259: F545F552

29. Osei SY, Price DA, Fisher ND, Porter L, Laffel LM, Hollenberg NK (1999) Hyperglycemia and angiotensin-mediated control of the renal circulation in healthy humans. Hypertension 33: 559-564

30. Walczyk MH, Pullian J, Bennett WM (1990) Effects of hyperglycemia and mannitol infusions on renal hemodynamics in normal subjects. Am J Med Sci 300: 218-224

31. Atherton A, Hill DW, Keen H, Young S, Edwards EJ (1980) The effect of acute hyperglycaemia on the retinal circulation of the normal cat. Diabetologia 18: 233-237

32. Grunwald JE, Riva CE, Martin DB, Quint AR, Epstein PA (1987) Effect of an insulin-induced decrease in blood glucose on the human diabetic retinal circulation. Ophthalmology 94: 1614-1620

33. Steinberg HO, Brechtel G, Johnson A, Fineberg N, Baron AD (1994) Insulin-mediated skeletal muscle vasodilation is nitric oxide dependent. J Clin Invest 94: 1172-1179

34. Scherrer U, Randin D, Vollenweider P, Vollenweider L, Nicod P (1994) Nitric oxide release accounts for insulin's vascular effects in humans. J Clin Invest 94: 2511-2515

35. Su EN, Yu DY, Alder VA, Cringle JS, Yu PK (1996) Direct vasodilatory effect of insulin on isolated retinal arterioles. Invest Ophthalmol Vis Sci 37: 2634-2644

36. Van den Enden MK, Nyengaard JR, Ostrow E, Burgan JH, Williamson JR (1995) Elevated glucose levels increase retinal glycolysis and sorbitol pathway metabolism. Implications for diabetic retinopathy. Invest Ophthalmol Vis Sci 36: $1675-1685$

37. Williams SB, Goldfine AB, Timimi FK et al. (1998) Acute hyperglycaemia attenuates endothelium-dependent vasodilation in humans in vivo. Circulation 97: 1695-1701

38. Mayhan WG, Patel KP (1995) Acute effects of glucose on reactivity of cerebral microcirculation: role of activation of protein kinase C. Am J Physiol 269: H1297-H1302

39. Renaudin C, Michoud E, Rapin JR, Lagarde M, Wiernsperger N (1998) Hyperglycemia modifies the reaction of microvessels to insulin in rat skeletal muscle. Diabetologia 41: 26-33

40. Norgaard K, Jensen T, Skott P et al. (1991) Effects of insulin on renal haemodynamics and sodium handling in normal subjects. Scand J Clin Lab Invest 51: 367-376

41. Engerman RL, Kern TS (1984) Experimental galactosemia produces diabetic like retinopathy. Diabetes 33: 97-100

42. Kern TS, Engerman RL (1987) Kidney morphology in experimental hyperglycemia. Diabetes 36: 244-249 
43. Pugliese G, Tilton RG, Speedy A et al. (1989) Effects of very mild versus overt diabetes on vascular hemodynamics and barrier function in rats. Diabetologia 32: 845-857

44. Vora JP, Owens DR, Ryder R, Atiea J, Luzio S, Hayes TM (1986) Effect of somatostatin on renal function. BMJ 292: 1701-1702

45. Tulassy T, Tulassy Z, Rascher W, Szücs L, Seyberth HW, Nagy I (1991) Effect of somatostatin on kidney function and vasoactive hormone systems in healthy subjects. Klin Wochenschr 69: 486-490

46. Vora JP, Owens DR, Luzio S, Atiera J, Ryder R, Hayes TM (1987) Renal responses to intravenous somatostatin in insulin-dependent diabetic patients and normal subjects, J Clin Endocrinol Metab 64: 975-979

47. Schmetterer L, Wolzt M (1998) Laser interferometric investigations of pulsatile choroidal blood flow: review and new results on the validity of the technique. J Biomed Opt 3: 246-252

48. Schmetterer L, Dallinger S, Findl O et al. (2000) A comparison between laser interferometric measurement of fundus pulsation and pneumotonometric measurement of pulsatile ocular blood flow. 1. Baseline considerations. Eye 14: 39-45

49. Schmetterer L, Dallinger S, Findl O et al. (2000) A comparison between laser interferometric measurement of fundus pulsation and pneumotonometric measurement of pulsatile ocular blood flow. 2. Effects of changes in pCO2 and pO2 and of isoproterenol. Eye 14: 46-52

50. Baron A, Tarshoby M, Hook G et al. (2000) Interaction between insulin sensitivity and muscle perfusion on glucose uptake in human skeletal muscle: evidence for capillary recruitment. Diabetes 49: 768-774 